\title{
PENGARUH BRAND PASSION, BRAND COMMITMENT DAN BRAND INTIMACY TERHADAP REPURCHASE INTENTION, POSITIVE WOM DAN PAY PRICE PREMIUM
}

\author{
Ali Wardhana ${ }^{1)}$ dan Samuel Shwan Terah ${ }^{2) *}$ \\ ${ }^{1)}$ Manajemen/Fakultas IImu Sosial dan Humaniora, Universitas Bunda Mulia \\ 2) Manajemen/Fakultas IImu Sosial dan Humaniora, Universitas Bunda Mulia
}

Diterima 14-02-2020 / Disetujui 4-03-2020

\begin{abstract}
Amid the pressures of industrial competition, emotions from consumers can be an unlimited resource that can create good opportunities. A brand can no longer be seen merely as an identity but as a relationship with consumers. Therefore, manufacturers are expected to wrap these emotions into a brand through the brand love concept. The usage of the concept of brand love is not without reason, but because brand love is the best representation of high-level constructs, one of which includes emotions. Thus this research aims to see how brand passion, brand intimacy and brand commitment build brand love and then have an impact on repurchase intentions, positive WOM and willingness to pay at premium prices on Samsung brands. This study uses primary data obtained through random questionnaire distribution and using target respondents of Samsung brand smartphone users. The results of this study indicate that brand love can be built well by brand passion, brand intimacy and brand commitment which are its dimensions. Brand love also shows that there is a positive relationship with intention to repurchase, positive WOM and willingness to pay at premium price. If it is more detailed then this study can conclude that brand commitment has the biggest contribution in building brand love and the biggest impact of brand love is positive WOM
\end{abstract}

Keywords: Brand Love, repurchase inteintion, positif wom and pay price premium

\begin{abstract}
ABSTRAK
Ditengah tekanan persaingan industri, emosi dari konsumen dapat menjadi sumberdaya yang tidak terbatas yang dapat menciptakan kesempatan yang baik. Merek tidak boleh lagi hanya dipandang sebagai sebuah identitas melainkan sebagai sebuah hubungan dengan konsumen. Oleh karena itu produsen diharapkan dapat membungkus emosi tersebut kedalam sebuah merek melalui konsep brand love. Penggunaan konsep brand love bukan tanpa alasan, melainkan karena brand love merupakan representasi paling baik dari konstruk tingkat tinggi yang salah satunya meliputi emosi. Dengan demikian penelitian ini bertujuan unuk melihat bagaimana brand passion, brand intimacy dan brand commitment membangun brand love dan kemudian berdampak pada niat pembelian ulang, positif WOM dan kesediaaan membayar pada harga yang lebih mahal pada merek Samsung. Penelitian ini menggunakan data primer yang diperoleh melalui pengedaran kuisoner secara acak dan menggunakan dengan target responden pengguna smartphone merek Samsung. Hasil penelitian ini menunjukan bahwa brand love mampu dibangun dengan baik oleh brand passion, brand intimacy dan brand commitment yang menjadi sub dimensinya. Brand love juga menunjukan bahwa terdapat hubungan yang positif dengan pada niat pembelian ulang, positif WOM dan kesediaaan membayar pada harga yang lebih mahal. Jika lebih terperinci maka dari penelitian ini dapat ditarik sebuah kesimpulan bahwa brand commitment memiliki kontribusi terbesar dalam membangun brand love dan dampak terbesar dari brand love adalah positif WOM.

Kata Kunci: brand love, niat pembelian ulang, positif wom dan kesediaan membayar pada harga premium.
\end{abstract}

\section{PENDAHULUAN}

Di tengah ketatnya industri telepon pintar setiap produsen akan berlomba-lomba untuk meningkatkan pembelian ulang dan positif WOM sebagai perwujudan dari kesetiaan merek.
Kedua variabel ini memainkan peran penting bagi keberlangsungan sebuah merek. Hal tersebut juga dialami oleh raja ponsel Indonesia menurut counterpoint reseach, dimana pada hasil penelitian tersebut menunjukan bahwa pada kuartal 2 tahun 2019, Samsung menguasai $27 \%$ pangsa pasar 
Indonesia (Sharma, 2019). Posisi tersebut tentu diharapkan oleh Samsung untuk dapat dipertahankan dengan berbagai cara, salah satunya dengan menggunakan emosi dari konsumen. Emosi diyakini dapat menjadi kesempatan yang baik untuk menyentuh konsumen dan dapat menjadi sumber daya yang tak terbatas (Robert, 2005). Lebih lanjut dalam bukunya Robert (2005) menyakini, emosi dapat menjadi pengalaman baru bagi konsumen dan dapat menimbulkan antusiasme yang luar biasa. Selain penggunaan emosi, produsen dapat menggunakan merek, namun bukan sebagai objek melainkan sebagai hubungan. Dengan menjadikan merek cara untuk menghubungkan antara produsen dan konsumen maka perusahaan dapat menciptakan difrensiasi dan loyalitas yang lebih besar (Bonchek dan France, 2016). Lebih lanjut, oleh Bonchek dan France (2016) mengungkapkan bahwa bila konsep merek yang tidak bukan hanya sebagai identitas tetapi juga sebagai penghubung dapat membantu menjelaskan dengan sangat baik tentang kebangkitan pemimpin pasar.

Hubungan kedua hal tersebut, yaitu ikatan emosi antara merek dan konsumen dapat dimaksimalkan melalui Lovemark (Pawle, dan Cooper, 2006). Mengingat lovemark berbicara mengenai ikatan emosi maka tidaklah mengherankan jika salah satu komponen pembentuk lovemark adalah brand love. Hal tersebut dikarenakan brand love merupakan representasi paling baik dari konstruk tingkat tinggi yang meliputi beragam kesadaran, emosi dan perilaku (Batra, 2012). Perlu dipahami juga bahwa , brand love menunjukan efek yang positif terhadap masing masing dimensi ekuitas merek dimana efek terbesarnya adalah loyalitas (Ortero dan Wilson, 2018).

Dengan terdukungnya loyalitas sebagai dimensi yang didukung oleh emosi konsumen maka hal tersebut akan menjadi dorongan untuk pembelian ulang dimasa yang akan datang (Ortero dan Wilson, 2018) Senada dengan penelitian Ortero dan Wilson, penelitian Giovanis dan Athanasopoulou (2018) juga mengungkap bahwa brand love yang tercermin dari brand passion, brand intimacy dan brand commitment memberi dampak pada lovemark dimana manifestasi dari lovemark adalah niat pembelian ulang, positif WOM dan kesediaaan membayar pada harga yang lebih mahal. Lantas bagaimana dengan smartphone merek Samsung? Apakah ikatan emosi yang tertuang dalam brand love terdapat pada merek Samsung dan dapat digunakan untuk mempengaruhi niat pembelian ulang, positif WOM dan kesediaaan membayar pada harga yang lebih mahal? Oleh karena itu berdasarkan latar belakang dan merujuk pada penelitian terdahulu maka penelitian ini akan bertujuan untuk mengetahui dampak brand love yang dibangun oleh brand passion, brand intimacy dan brand commitment terhadap niat pembelian ulang, positif WOM dan kesediaaan membayar pada harga yang lebih mahal pada merek Samsung.

\section{TINJAUAN PUSTAKA}

\section{Brand Commitment}

Komitmen pada penelitian ini didefinisikan sebagai kesediaan konsumen untuk meningkatkan dan mempertahankan ikatan afektif dengan merek yang membuat konsumen merasa hangat dan menyenangkan dimana komitmen tersebut terbagi menjadi dua yaitu komitmen afektif dan kelangsungan komitmen (Ercis et al, 2012). Penelitian Ercis et al (2012) lebih lanjut mengungkapkan bahwa komitmen afektif didasarkan pada identifikasi dan nilai yang dibagi oleh merek dan komitmen ini mampu menjelaskan keterikatan mendalam dengan merek yang difokuskan, sedangkan komitmen berkelanjutan didefinisikan sebagai perasaan lemah konsumen terhadap suatu merek. Dengan demikian sudah seharusnya para pemegang kebijakan memiliki pemahaman lebih akan brand commitment. 
Brand commitment juga dapat didefinisikan sebagai emosional atau keterikatan psikologi terhadap suatu merek yang diyakini bukan hanya menjadi elemen kunci dalam meprediksi kestabilan hubungan antara merek (Dass 2015). Dengan hubungan yang stabil maka tidak mengherankan jika brand commitment dapat mendorong loyalitas konsumen dan pembelian ulang (Dass 2015). Senada dengan itu Ercis et al (2012) menungkapkan bahwa brand commitment bersama dengan brand trust dijelaskan sebagai antesenden dari loyalitas dan niat pembelian kembali. (Ercis et al, 2012).

$H_{I}$ : brand commitment berpengaruh terhadap brand love.

\section{Brand Passion}

Brand passion didefinisikan sebagai konstruksi psikologis yang terdiri dari antusiasme yang besar, kekaguman terhadap suatu hal, obsesi terhadap merek danperasaan yang dianut oleh beberapa konsumen dan kemudian menjadi inti dari kekuatan dan hubungan konsumen dengan merek yang berkualitas tinggi (Swimberghe et al, 2014). Lebih lanjut di jelaskan jika brand passion memberikan positif WOM dan lebih bersedia membayar harga premium untuk merek tersebut (Swimberghe et al, 2014).

$\mathrm{H}_{2}$ : brand passion berpengaruh terhadap brand love.

\section{Brand Intimacy}

Keintiman merek didefinisikan sebagai tingkat dimana merek berinteraksi secara psikologis dekat dengan pelanggannya sehingga tidak mengherankan jika keintiman merek memiliki hubungan yang signifikan dengan perilaku niat beli pada konsumen (Barcelos et al, 2016). Keintiman sendiri merupakan sub dimensi dari brand love yang memiliki rasa kedekatan dan keterikatan pada serta memiliki keingingan yang kuat untuk membeli atau membeli kembali merek dan berkomitmen, setidaknya dalam jangka pendek, untuk mendukung merek tertentu (Giovanis dan Athanasopoulou, 2018). $\mathrm{H}_{3}$ : brand intimacy berpengaruh terhadap brand love.

Brand Love

Brand love merupakan turunan dari cinta interpersonal, namun perlu disadari bahwa tidak semua unsur cinta interpersonal masuk kedalam brand love (Pandir dan Yasin 2017). Serupa dengan cinta interpersonal brand love juga berbicara tentang hubungan jangka panjang konsumen dengan suatu merek dan ketika kepuasan konsumen untuk suatu produk atau merek berubah menjadi cinta maka akan tercipta kepuasan yang kuat (unal dan Aydin, 2013).

Brand love memiliki dampak terhadap beberapa hal, salah satunya adalah tingkat pembelian. Konsumen yang memiliki brand love yang lebih tinggi akan melakukan pembelian terhadap merek yang mereka cintai paling tidak satu kali (Pandir dan Yasin 2017). Penelitian terdahulu juga mengungkapkan bahwa brand love berdampak signifikan terhadap niat pembelian ulang dan positif WOM (Fetscherin, 2014). Dengan demikian dapat disusun hipotesis sebagai berikut :

$H_{4}$ : brand love berpengaruh terhadap niat pembelian ulang, positif WOM dan kesediaan membayar pada harga yang lebih mahal.

Merujuk pada tinjauan pustaka tersebut maka diperolehlah rerangka pemikiran sebagai berikut :

\section{METODE PENELITIAN}

Pada penelitian target sampel berada pada rentang lebih dari 30 dan kurang 500 (Sekaran dan Bougie, 2016) dimana proses pengambilan sampel akan dilakukan pada satu titik waktu tertentu atau dengan kata lain penelitian ini merupakan penelitian cross sectional (Leavy, 2017). 
Gambar 1 : Rerangka pemikiran

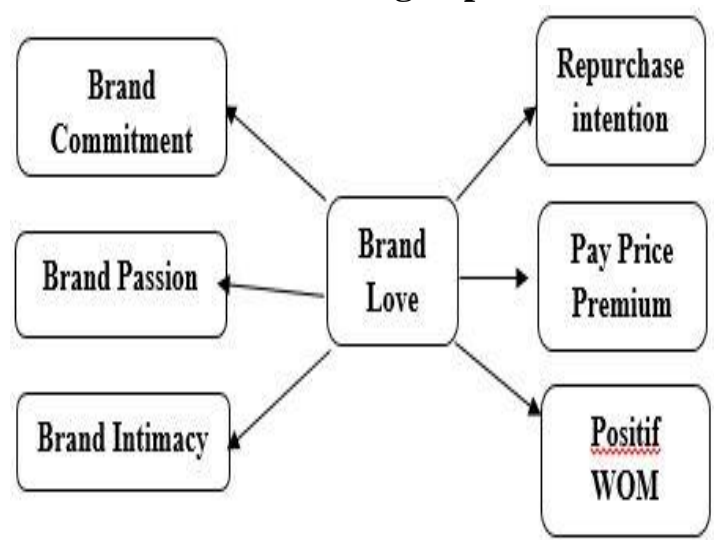

Sumber : Giovanis dan Athanasopoulou,

(2018) dengan pengurangan variabel

Data dalam penelitian ini adalah data primer yang akan diperoleh melalui kuesioner secara luring dengan target responden adalah pengguna telepon pintar merek Samsung tanpa membatasi tempat pengambilan sampel. Dalam kuisoner yang disebar, setiap item kuisoner akan menggunakan skala rating yang umum digunakan yaitu skala Likert yang memang didesain untuk menguji seberapa kuat responden setuju dengan sebuah pernyataan dengan mengikuti pola $1=$ sangat tidak setuju, $2=$ tidak setuju, $3=$ netral, $4=$ setuju dan $5=$ sangat setuju (Sekaran dan Bougie, 2016).

Data yang diperoleh tidak akan langsung diolah melainkan terlebih dahulu menyingkirkan data outlier. Setelah eliminasi data outlier maka dilakukan uji validitas dan reliabilitas alat ukur terlebih dahulu. Validitas konstruk diukur dengan menggunakan nilai average variance extracted (AVE) dimana yang nilai dari AVE seharusnya lebih besar dari 0,5 (Hair et al., 2014). Pada uji reliabilitas akan diukur dengan menggunakan Composite Reliability dan Cronbach's Alpha yang nilai diharapkan diatas 0,7 agar memberikan bukti yang memadai untuk konsistensi internal (Hair et al., 2014). Secara keseluruhan data akan diuji dan dianalisis dengan pendekatan pendekatan partial least square-structural equation modeling (PLSSEM).

Pada penelitian ini diperoleh 110 sampel yang kemudian 10 sampel dieliminasi sehingga tersisa 100 sampel. Data tersebut kemudian perlu dilakukan penggambaran responden dengan berfokus pada katergori gender, usia dan lama penggunaan. Pada kategori gender diperoleh sebanyak 69\% responden memiliki gender wanita, sedangkan pada kategori usia diperoleh sebanyak $37 \%$ responden pada rentang usia 16-20 tahun. Pada kategori usia juga nampak bahwa $30 \%$ responden berada pada rentang usia 21-25 tahun. Dengan dominasi kedua usia ini maka tidaklah mengherankan jika $47 \%$ responden bekerja sebagai pelajar/mahasiswa. Kategori terakhir adalah lama penggunaan, dimana $44 \%$ responden pada penelitian ini sudah menggunakan smartphone merek Samsung diatas 4 tahun. Jika ditarik kesimpulannya maka dapat dikatakan bahwa profil responden pada penelitian ini didominasi oleh wanita, generasi muda pada rentang usia 16-20 tahun, memiliki profesi pelajar atau mahasiswa dengan lama penggunaan lebih dari 4 tahun.

$$
\text { Langkah berikut usai }
$$

menggambarkan profil adalah melakukan serangkaian uji untuk memastikan bahwa korelasi setiap variabel dan alat ukur yang 
digunakan memiliki keandalan. Pada uji validitas diskriminan menggunakan kriteria Fornell Larcker dimana nilai akar kuadrat
AVE setiap konstruk harus lebih besar dari pada nilai korelasi antar konstruk dalam model (Ghozali dan Latan, 2015).

Tabel 1 Kriteria Fornel Larcker

\begin{tabular}{lccccccc}
\hline & $\begin{array}{c}\text { Brand } \\
\text { Commitment }\end{array}$ & $\begin{array}{c}\text { Brand } \\
\text { Intimacy }\end{array}$ & $\begin{array}{c}\text { Brand } \\
\text { Love }\end{array}$ & $\begin{array}{c}\text { Brand } \\
\text { Passion }\end{array}$ & $\begin{array}{c}\text { Pay Price } \\
\text { Premium }\end{array}$ & $\begin{array}{c}\text { Positive } \\
\text { WOM }\end{array}$ & $\begin{array}{c}\text { Repurchase } \\
\text { Intention }\end{array}$ \\
\hline $\begin{array}{l}\text { Brand } \\
\text { Commitment }\end{array}$ & 0,891 & & & & & & \\
\hline Brand Intimacy & 0,528 & 0,945 & & & & & \\
\hline Brand Love & 0,873 & 0,749 & 0,836 & & & & \\
\hline Brand Passion & 0,718 & 0,503 & 0,827 & 0,833 & & & \\
\hline $\begin{array}{l}\text { Pay Price } \\
\text { Premium }\end{array}$ & 0,556 & 0,479 & 0,646 & 0,604 & 0,930 & & \\
\hline Positive WOM & 0,730 & 0,539 & 0,766 & 0,734 & 0,722 & 0,954 & \\
\hline $\begin{array}{l}\text { Repurchase } \\
\text { Intention }\end{array}$ & 0,701 & 0,532 & 0,755 & 0,698 & 0,830 & 0,730 & 0,875 \\
\hline
\end{tabular}

\section{HASIL DAN PEMBAHASAN}

Setelah melakukan uji validitas maka selanjutnya dapat di lakukan uji reliabilitas dimana pada uji ini akan menggunakan nilai cronbach's alpha dimana item yang diukur dapat diterima bila nilai chonbach's alpha pada rentang 0,6 sampai 0,7 namun akan

Tabel 2 Hasil Uji Reliabilitas

\begin{tabular}{lll}
\hline & CA & CR \\
\hline Brand Commitment & 0,871 & 0,921 \\
\hline Brand Intimacy & 0,939 & 0,961 \\
\hline Brand Love & 0,783 & 0,874 \\
\hline Brand Passion & 0,860 & 0,914 \\
\hline Pay Price Premium & 0,922 & 0,951 \\
\hline Positive WOM & 0,951 & 0,968 \\
\hline Repurchase Intention & 0,898 & 0,929 \\
\hline
\end{tabular}

Hasil uji validitas dan reliabilitas menunjukan bahwa indikator yang digunakan dalam penelitian ini memiliki validitas yang memadai, yang bearti alat ukur dalam penelitian ini sudah tepat dan eluruh indikator dapat dinyatakan memiliki reliabilitas internal yang cukup yang bearti instrumen yang digunakan untuk mengukur dapat dikatakan stabil dan konsisten. Dengan hasil uji validitas dan reliabilitas yang baik maka data lebih baik jika nilai tersebut diatas 0,8 (Sekaran dan Bougie, 2016). Uji validitas pada penelitian ini tidak hanya menggunakan nilai cronbach's alpha melainkan juga menggunakan nilai composite reliability dimana nilai hasil uji diharapkan diatas 0.7 (Ghozali dan Latan, 2015).

yang digunakan sudah relevan dan dapat di lakukan pengujian hipotesa, sebagai berikut :

Pada hipotesa pertama yaitu brand commitment berpengaruh terhadap brand love memberikan hasil terdukung karena nilai $\mathrm{p}$ dibawah 0,05 dan nilai $t$ hitung sebesar 12,053 diatas $t$ tabel sebesar 1,986. Pada hipotesa kedua yaitu brand passion berpengaruh terhadap brand love memberikan hasil terdukung karena nilai $\mathrm{p}$ dibawah 0,05 dan nilai t hitung sebesar 6,093 diatas t tabel sebesar 1,986. Pada hipotesa ketiga yaitu brand intimacy berpengaruh terhadap brand love. memberikan hasil terdukung karena nilai $\mathrm{p}$ dibawah 0,05 dan nilai $\mathrm{t}$ hitung sebesar 6,489 diatas $t$ tabel sebesar 1,986. Dengan terdukungnya ketiga hipotesa ini maka dapat dikatakan bahwa brand commitment, brand passion, brand intimacy merukapan sub dimensi yang mampu membangun brand love dimana hasil ini mengkonfirmasi penelitian terdahulu dari penelitian Giovanis dan Athanasopoulou (2018). 
Tabel 3 Hasil Uji Hipotesis untuk Variabel yang membangun Brand Love

\begin{tabular}{lccl}
\hline Hipotesis & Koefisien Jalur & t hitung & Hasil \\
\hline Brand Commitment -> Brand love & 0,000 & 12,053 & Terdukung \\
\hline Brand Passion -> Brand love & 0,000 & 6,093 & Terdukung \\
\hline Brand Intimacy -> Brand love & 0,000 & 6,489 & Terdukung \\
\hline
\end{tabular}

Pada hipotesis terakhir yaitu brand love berpengaruh terhadap niat pembelian ulang, positif WOM dan kesediaan membayar pada harga yang lebih mahal juga terdukung dengan nilai $p$ dibawah 0,05 dan nilai t hitung diatas $\mathrm{t}$ stastik sebesar 1,986. Secara rinci hasil uji hipotesis kempat ini dapat dilihat pada tabel dibawah ini

Tabel 4 Hasil Uji Hipotesis untuk Variabel yang membangun Brand Love

\begin{tabular}{lccl}
\hline Hipotesis & Koefisien Jalur & t hitung & Hasil \\
\hline Brand love -> Repurchase Intention & 0,000 & 12,055 & Terdukung \\
\hline Brand love -> Positive WOM & 0,000 & 16,557 & Terdukung \\
\hline Brand love -> Pay Price Premium & 0,000 & 7,929 & Terdukung \\
\hline
\end{tabular}

\section{SIMPULAN}

Melalui penelitian ini dapat memberikan kontribusi berupa konfirmasi yang menguatkan untuk penelitian terdahulu dimana pada penelitian ini brand love terbukti mampu dibangun oleh ketiga sub dimensinya, yaitu brand commitment, brand passion, dan brand intimacy. Jika melihat lebih dalam lagi maka nampak bahwa brand commitment memberikan dampak yang paling besar. Hal ini dapat diartikan keterikatan psikologi terhadap suatu merek perlu mendapat perhatian bagi para produsen yang menginginkan terciptanya brand love. Besarnya dampak brand commitment juga dapat dilihat sejalan penelitian Unal dan Aydin (2013) yang mengungkapkan bahwa brand love merupakan hubungan jangka panjang konsumen dengan suatu merek dan dengan demikian memerlukan keterikatan psikologi yang terdapat pada brand commitment.

Hasil penelitian ini juga mengungkapkan bahwa brand love memberikan dampak terbesar pada positif WOM namun memberikan dampak terkecil pada kesediaan membayar harga yang lebih mahal. Hal ini berkontribusi pada 2 hal, yaitu brand love khususnya pada merek Samsung dapat digunakan untuk memberikan dampak kepada konsumen dan mengakuisisi konsumen baru. Kontribusi kedua muncul pada hasil minimnya dampak brand love terhadap kesediaan membayar harga yang lebih mahal yang dapat digunakan pada penelitian yang akan datang dengan target responden yang memiliki pendapatan tertentu. Dengan 37\% responden pada rentang usia 16-20 tahun dan 30\% responden berada pada rentang usia 21-25 tahun peneliti menyakini kelompok responden ini belum memiliki kemampuan untuk membayar smartphone yang lebih mahal sehingga bila penelitian yang akan datang menargetkan responden dengan pendapatan tertentu akan memberikan hasil yang berbeda.

\section{DAFTAR PUSTAKA}

Barcelos, R., Dantas, D., Sénécal, S., \& Rossi, C. (2016). The Effect of Brand Intimacy on Consumer Responses: An Application on a Social Media Context. In Rediscovering the Essentiality of 
Marketing (pp. 209-214). Springer, Cham.

Batra, R., Ahuvia, A., \& Bagozzi, R. P. (2012). Brand love. Journal of marketing, 76(2), 1-16.

Bonchek, M dan France, C. 2016. Build Your Brand as a Relationship. https://hbr.org/2016/05/build-yourbrand-as-arelationship?referral $=03759 \& \mathrm{~cm} \_v \mathrm{vc}=\mathrm{rr}$ item_page.bottom. diakses pada tanggal 10 Februari 2020

Dass, K. A. B. M. (2015). An investigation of the effects of product recalls on brand commitment and purchase intention. Journal of Consumer Marketing, 32(1), 1-14.

Erciş, A., Ünal, S., Candan, F. B., \& Yildırım, H. (2012). The effect of brand satisfaction, trust and brand commitment on loyalty and repurchase intentions. Procedia-Social and Behavioral Sciences, 58, 1395-1404.

Fetscherin, M. (2014). What type of relationship do we have with loved brands?. Journal of Consumer Marketing.

Giovanis A dan Athanasopoulou P, (2018) "Understanding lovemark brands: Dimensions and effect on Brand loyalty in high-technology products", Spanish Journal of Marketing - ESIC, Vol. 22 Issue: 3, pp. 272-294

Ghozali, I., \& Latan, H. (2015). Partial Least Squares, Konsep, Teknik dan aplikasi menggunakan program SmartPLS 3.0. Badan Penerbit - Undip.

Hair, J. F., Black, W. C., Babin, B. J., \& Anderson, R. E. (2014). Multivariate data analysis: Pearson new international edition. Pearson Higher Ed

Leavy, P. (2017). Research Design : Quantitative, Qualitative, Mixed Methods, Arts-Based, and CommunityBased Participatory Research Approaches. The Guilford Press : New York

Otero, C., \& Wilson, G. P. (2018). Effects of brand love and brand equity on repurchase intentions of young consumers. International Review of Management and Marketing, 8(4), 7.

Pandir, B., \& Yasin, B. (2017). Brand love and customer engagement's role over brand loyalty. Journal of Management Marketing and Logistics, 4(4), 359-365.

Pawle, J., \& Cooper, P. (2006). Measuring emotion-lovemarks, the future beyond brands. Journal of advertising research, 46(1), 38-48.

Pandir, B., \& Yasin, B. (2017). Brand love and customer engagement's role over brand loyalty. Journal of Management Marketing and Logistics, 4(4), 359-365.

Roberts, K. (2005). Lovemarks: The future beyond brands. Powerhouse books.

Sekaran, U., \& Bougie, R. (2016). Research methods for business: A skill building approach. John Wiley \& Sons

Sharma, P2019. Indonesian Smartphone Market Grew 6\% annually in Q2 2019

https://www.counterpointresearch.com/i ndonesian-smartphone-market-grew-6annually-q2-2019/ diakses pada tanggal 10 Februari 2020

Swimberghe, K. R., Astakhova, M., \& Wooldridge, B. R. (2014). A new dualistic approach to brand passion: Harmonious and obsessive.

Unal, S., \& Aydin, H. (2013). An investigation on the evaluation of the factors affecting brand love. ProcediaSocial and Behavioral Sciences, 92, 7685. 